\title{
Evolution of liquid bridge rupture in the evaporator model
}

\author{
Elizaveta Gatapova ${ }^{1,2, *}$, Alyona Novikova ${ }^{1,3}$ \\ ${ }^{1}$ Kutateladze Institute of Thermophysics SB RAS, Novosibirsk, Russia \\ ${ }^{2}$ Novosibirsk State University, Novosibirsk, Russia \\ ${ }^{3}$ Novosibirsk State Technical University, Novosibirsk, Russia
}

\begin{abstract}
The liquid bridge rupture confined between two glass plates is experimentally investigated. High-resolution shadow technique is used for video registration. Critical bridge diameters and distance between glass plates are found.
\end{abstract}

\section{Introduction}

The development of new technological potential for high-performance cooling systems with manipulation of phase-change at liquid-vapor interfaces for microelectronics and Light Emitting Diodes is highly required by the global miniaturization [1] and by growing up of heat flux densities. Active and passive cooling methods with phase transitions are available, such as microchannel flows [2-4] and heat pipes [5, 6]. Effects near liquid-vaporsolid contact lines $[7,8]$, as well as temperature jump, which can present near the vapor bubbles [9-11] become important for such systems. The use of different nanocoatings can enhance heat transfer in cooling systems of small size [12].

Investigations of the behavior of the liquid bridges and meniscus occurring in heat pipe are one of the important problems for stable operation of heat pipes. For example, the highest intensity of heat transfer provided by evaporation of a thin liquid film that separates the vapor bubble from the heating surface in the pulsating heat pipe (PHP). The vapor bubbles are formed when the liquid is heated in PHP. The critical temperature difference between the heat source and the heat sink leads to auto-oscillations of the vapor bubbles and liquid plugs present inside the capillary tube $[5,13]$. Heat is thus passively transferred, not only by latent heat exchange like in conventional heat pipes, but also by sensible heat transfer between the wall and the fluid. The oscillations are extremely important because they cause a significant increase in heat transfer intensity in comparison with other types of heat pipes [13]. Nowadays, PHP is most reliable and cheap compared to other heat transfer devices.

The processes of liquid transfer between two solid surfaces, formation of liquid bridge and finally formation and evaporation of droplet are important problems for application in PHP. In this paper, we present the results of the experiment on dynamics of liquid bridge confined between two surfaces.

\footnotetext{
*Corresponding author: gatapova@itp.nsc.ru
} 


\section{Experimental setup}

The scheme of experimental setup is presented in Fig. 1. To study the dynamics of the liquid bridge the shadow technique providing a resolution of $3 \mu \mathrm{m}$ per pixel is adopted. The test cell consists of two plates of round shape. Bottom plate has a hole of a diameter less than $1 \mathrm{~mm}$ for a liquid injection. The optical glasses BK7 with a diameter of $50 \mathrm{~mm}$ are used for experiments. The contact angle of water on BK7 is $40^{\circ}$; contact angle hysteresis is $25^{\circ}$, which are characterized by DSA-100, KRUSS. Ultrapure water (MilliQ) is used as a working fluid. The liquid is injected from a bottom using a high-precision syringe pump (Cole Parmer) and liquid bridge confined between two surfaces is formed (Fig. 2a). The linear micro-positioner (Zaber) travels one of the plates changing and controlling the distance between surfaces. We have put some changes in $\mathrm{C} \#$ to micro-positioner console. Experiments are conducted at normal atmospheric condition. Air humidity and temperature in vicinity of the test cell are controlled by Testo device.

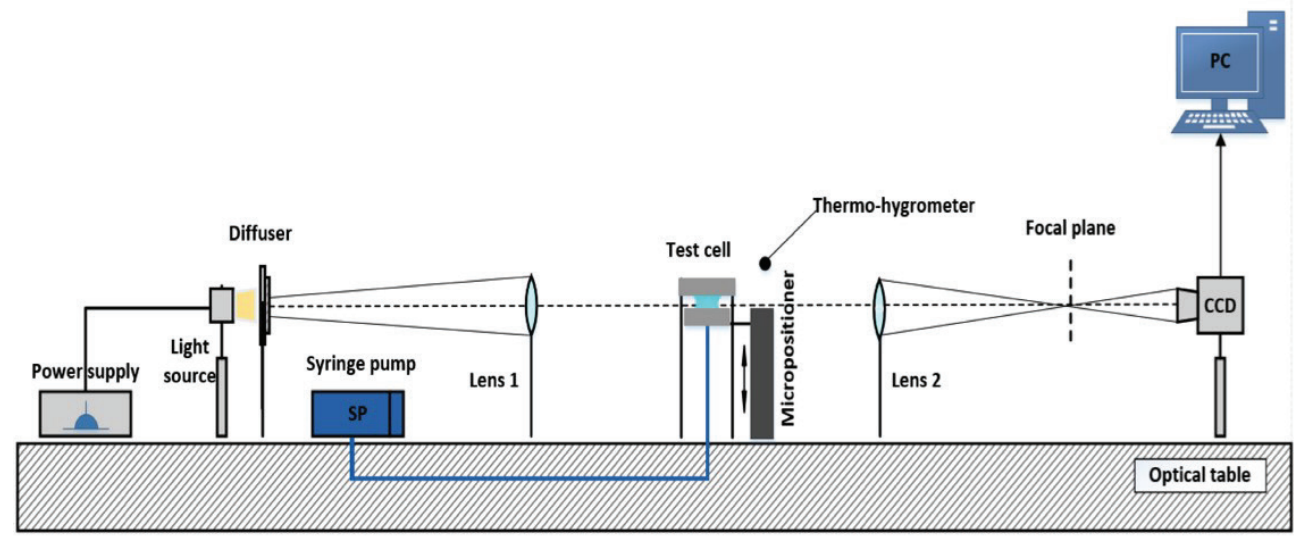

Fig. 1. Scheme of the experimental setup and apparatus.

\section{Measurements technique and results}

In the present experiments the liquid of volume of $21 \mu \mathrm{l}$ is injected through a bottom hole with a rate of $0.5 \mu \mathrm{l} / \mathrm{s}$ into the test cell. The liquid bridge confined between two surfaces is formed with a practically the same contact angles at the top and bottom plates. The pressure, temperature and humidity of air were $100.5 \mathrm{kPa}, 26.8{ }^{\circ} \mathrm{C}$ and $23.8 \%$, respectively. In order to investigate an evolution of the liquid bridge and contact angles with the changing the distance between two plates the following procedure is organized. The lower plate of the test cell is moved downwards by Zaber micro-positioner with the speed of $40 \mu \mathrm{m} / \mathrm{s}$ until the rupture of the liquid bridge (Fig. 2a, b, c).

Fig. 3 demonstrates evolutions of the two base diameters $\left(D_{\mathrm{t}}, D_{\mathrm{b}}\right)$, middle diameter $\left(D_{\mathrm{m}}\right)$ and height of liquid bridge $(H)$ in real time. The middle diameter of the liquid bridge is decreasing linearly, while the top and bottom base diameters are decreasing until a critical value. Then the pinning at the top and bottom plates is observed, while the liquid bridge height is increased. 


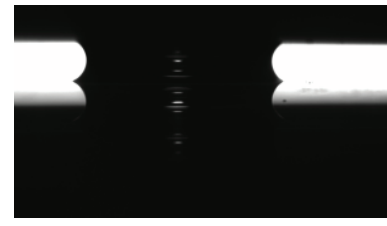

$a$

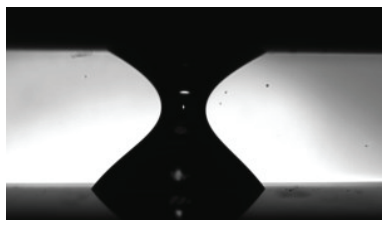

$b$

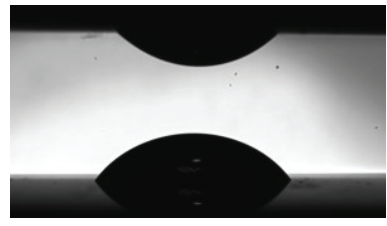

$c$

Fig. 2. Evolution of liquid bridge: $a$ - initial position; $b$ - just before the break; $c$ - break and the formation two liquid droplets.

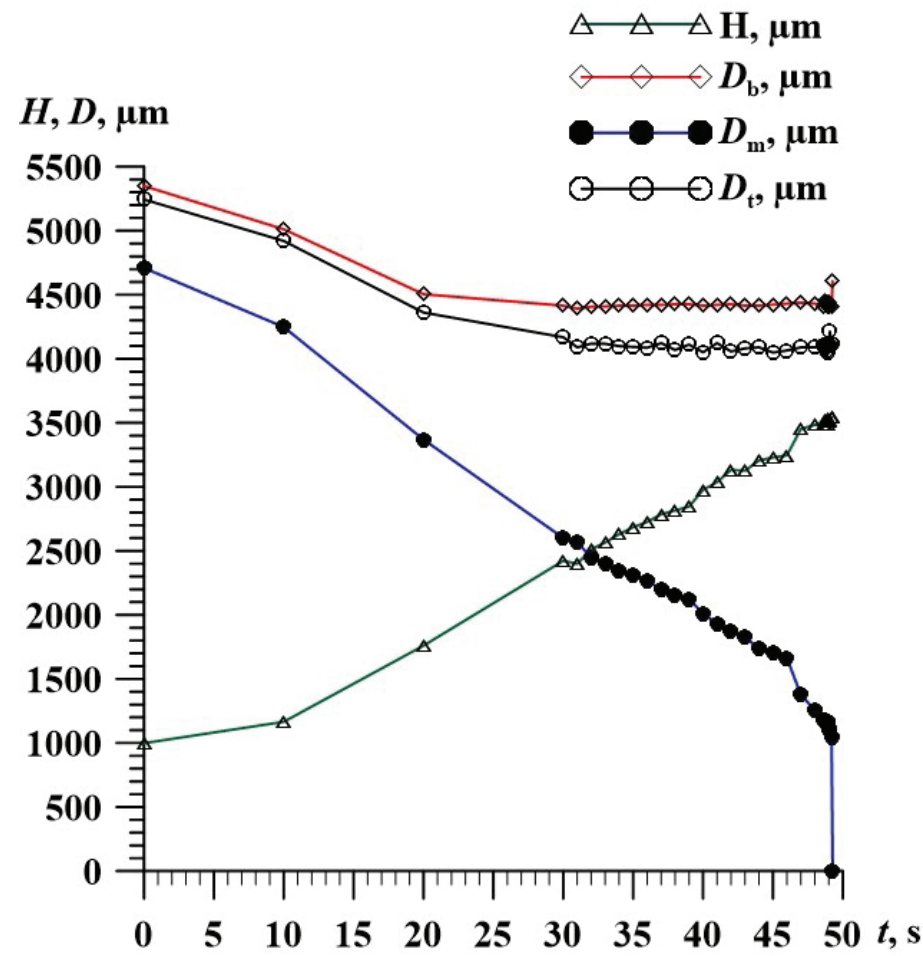

Fig. 3. Evolutions of liquid bridge height and diameters in real time.

In conclusion, the dynamics of liquid bridge rupture between two glass plates is experimentally investigated. High-resolution shadow technique is used for video registration. The pinning at the top and bottom plates is observed for certain distance between the plates until the liquid bridge rupture. While the height and middle diameter change practically linearly. The critical middle diameter to rupture is $1 \mathrm{~mm}$ at a moving speed of $40 \mu \mathrm{m} / \mathrm{s}$ and initial liquid volume of $21 \mu \mathrm{l}$ for particular experiment on BK7 with contact angle hysteresis of $25^{\circ}$.

The authors gratefully acknowledge the support of this work by the Ministry of Education and Science of the Russian Federation (Agreement 14.616.21.0016, project identifier RFMEFI61614X0016). 


\section{References}

1. T.M. Squires and S.R. Quake, Review of Modern Physics, 77, 977 (2005)

2. O.A. Kabov, E.Ya. Gatapova, D.V. Zaitsev, 11th IEEE Intersociety Conference on Thermal and Thermomechanical Phenomena in Electronic Systems, I-THERM 2008, Article number 4544312, 520 (2008)

3. E.Ya. Gatapova, O.A. Kabov, International Journal of Heat and Mass Transfer, 51, 4797 (2008)

4. A. Bar-Cohen and G.A. Holloway, Interfacial Phenomena and Heat Transfer, 3, 393 (2015)

5. H. Akachi, U.S. Patent, Patent Number 4921041, (1990)

6. M.A. Chernysheva, S.I. Yushakova, Y.F. Maydanik, International Journal of Heat and Mass Transfer, 81, 297 (2015)

7. E.Ya. Gatapova, O.A. Kabov, Microgravity Science and Technology, 19, 132 (2007)

8. S.S. Panchamgam, A. Chatterjee, J.L. Plawsky, P.C. Wayner, Jr., International Journal of Heat and Mass Transfer, 51, 5368 (2008)

9. E.Y. Gatapova, I.A. Graur, F. Sharipov, O.A. Kabov, International Journal of Heat and Mass Transfer, 83, 235 (2015)

10. E.Y. Gatapova, R.A. Filipenko, Y.V. Lyulin, I.A. Graur, I.V. Marchuk, O.A. Kabov, Thermophysics and Aeromechanics, 22, 701 (2015)

11. E.Y. Gatapova, I.A. Graur, O.A. Kabov, V.M. Aniskin, M.A. Filipenko, F. Sharipov, L. Tadrist, International Journal of Heat and Mass Transfer, 104, 800 (2017)

12. N. Miljkovic, R. Enright, Y. Nam, K. Lopez, N. Dou, J. Sack, E.N. Wang, Nano Letters, 13, 179 (2013)

13. L.L. Vasiliev, Applied Thermal Engineering, 25, 1 (2005) 